\title{
Processing, structure and flexural strength of CNT and carbon fibre reinforced, epoxy-matrix hybrid composite
}

\author{
K CHANDRA SHEKAR ${ }^{1}$, M SAI PRIYA ${ }^{2}$, P K SUBRAMANIAN ${ }^{2}$, ANIL KUMAR ${ }^{3}$, \\ B ANJANEYA PRASAD ${ }^{4}$ and N ESWARA PRASAD ${ }^{5, *}$ \\ ${ }^{1}$ Department of Mechanical Engineering, Vignan Institute of Technology and Science, Deshmukhi, \\ Hyderabad 508 284, India \\ ${ }^{2}$ Department of Metallurgical and Materials Engineering, Mahatma Gandhi Institute of Technology, Gandipet, \\ Hyderabad 500 075, India \\ ${ }^{3}$ Advanced Systems Laboratory, DRDO, P. O. Kanchanbagh, Hyderabad 500 058, India \\ ${ }^{4}$ Department of Mechanical Engineering, Jawaharlal Nehru Technological University, Hyderabad 500 085, India \\ ${ }^{5}$ Regional Centre for Military Airworthiness (Materials), CEMILAC, DRDO, P. O. Kanchanbagh, \\ Hyderabad 500 058, India
}

MS received 12 June 2012; revised 30 July 2013

\begin{abstract}
Advanced materials such as continuous fibre-reinforced polymer matrix composites offer significant enhancements in variety of properties, as compared to their bulk, monolithic counterparts. These properties include primarily the tensile stress, flexural stress and fracture parameters. However, till date, there are hardly any scientific studies reported on carbon fibre $\left(\mathrm{C}_{\mathrm{f}}\right)$ and carbon nanotube $(\mathrm{CNT})$ reinforced hybrid epoxy matrix composites (unidirectional). The present work is an attempt to bring out the flexural strength properties along with a detailed investigation in the synthesis of reinforced hybrid composite. In this present study, the importance of alignment of fibre is comprehensively evaluated and reported. The results obtained are discussed in terms of material characteristics, microstructure and mode of failure under flexural (3-point bend) loading. The study reveals the material exhibiting exceptionally high strength values and declaring itself as a material with high strength to weight ratio when compared to other competing polymer matrix composites (PMCs); as a novel structural material for aeronautical and aerospace applications.
\end{abstract}

Keywords. Epoxy composites; carbon fibre; CNT; hand lay-up technique; unidirectional weaving; microstructure; flexural strength.

\section{Introduction}

Advanced materials have assumed significant technological importance in applications areas such as structural materials in recent years due to the demand for efficient working and enhanced mechanical properties. Among several ways to achieve the above mentioned properties, processing of material based on fibre reinforcements has been the most effective (John and Karl 1982; Herrera and Valadez 2004). These properties include high strength to weight ratio, fracture toughness properties, electrical properties, etc that influence the efficiency of any working component. Among the newer structural composites developed, much significance has been given to the PMCs from the last few decades owing to their excellent specific strength and specific modulus properties. PMCs

\footnotetext{
*Author for correspondence (nep@ cemilac.drdo.in)
}

such as epoxy matrix hybrid composite with dual reinforcement of carbon fibres and CNT manufactured via hand lay up (HLU) technique (unidirectional) was seen to increase the overall fracture toughness and strength parameters when compared to other trending structural composites (Eswara Prasad et al 2004; Chandra Shekar et al 2013).

Flexural strength is one of the most widely used properties in characterizing the mechanical behaviour of composites. Standard test methods are adopted for the property evaluation of composite materials as specified by ASTM at ambient temperatures. Most of the testing conducted and the tests reported in this paper are according to the standard procedures. In the present study, flexural behaviour of the unidirectional $C_{\mathrm{f}}$ and CNT reinforced, epoxy matrix hybrid composite is evaluated in detail in order to determine the influence of directionality of fibres. The results obtained are rationalized based on materials' characteristics and mode of failure. 


\section{Experimental}

\subsection{Materials}

Diglycidyl ether of bisphenol-A (DGEBA) epoxy resin and diethyl toluene diamene (DETDA) hardener were used as matrix system. T-700 carbon fiber tows with ultimate tensile strength of $4800 \mathrm{MPa}$ and amino functionalized multi walled carbon nanotubes $(20-30 \mathrm{~nm}$ diameter and lengths of $2-4 \mu \mathrm{m}$ ) were used as reinforcing materials. The synthesis was via conventional hand lay up technique (Timothy Gutowski et al 1994).

\subsection{Material processing}

Initially, epoxy resin diglycidyl ether of bisphenol-A (DGEBA) was the precursor material for base matrix. Amino functionalized multi walled carbon nanotubes were taken in a proportion of $0.5 \mathrm{wt} \%$ epoxy mixture. Proportional amount (i.e. $24 \mathrm{wt} \%$ of the epoxy resin) of diethyl toluene diamine (DETDA) hardener (industrial designation - LY5200) was mixed to the above epoxy mixture. Dispersion of CNTs was ensured by sonication with a probe type sonicator (Mesonix-3000, USA) for 45 min followed by planetary ball milling (Insmart systems, India) for $3 \mathrm{~h}$ at $250 \mathrm{rpm}$.

The carbon fibres ( $6 \mu \mathrm{m}$ diameter) 3000 filaments in number constituting a single 'tow' and several of such tows were used for winding. Traditional hand lay-up technique was employed with alternative layers of matrix mixture (epoxy and CNTs) and carbon fibers. A hardened steel plate $(200 \times 150 \mathrm{~mm})$ served as the base for the winding of the carbon fibres and application of the resin mixture. The steel plate was covered with a layer of TEFLON in order to facilitate the easy removal of the component after the densification and also to prevent the densification of the fibers along the steel plate. A coating of this mixture was applied to the TEFLON on the steel plate. Winding of fibers was carried out on the TEFLON layer. The fibers were wound over the plate with overlapping layers, leaving no air gaps between the strands. After every single layer covering of the fiber strands, a thorough layer of resin mixture was applied on it with the help of a paint brush. The procedure was repeated until the desired thickness of $3.4 \mathrm{~mm}$ was obtained. Additional resin was applied wherever required to cover the fiber winding. Hand pressure was used to make sure the resin saturated and fully wetted all layers, and any air pockets were removed. The excess of resin mixture was drained out of fibers and resin system by applying pressure on steel plate support blocks and tightened with screw. The whole set up was left aside for $12 \mathrm{~h}$ to allow the excess resin mixture to drain out completely. The synthesis process concluded by the curing process given in three heat treatment cycles in a muffle furnace is shown above in figure 1.

\section{$2.3 \quad$ Flexural testing}

Specimens of rectangular cross section with an approximate width of $10 \mathrm{~mm}$, thickness of $3.4 \mathrm{~mm}$ and length of $75 \mathrm{~mm}$ (with an included span length equivalent to 16 times the thickness ( $54 \mathrm{~mm}$ here) ) were used to determine the flexural properties of the hybrid composite material. This procedure was followed as specified by the ASTM standard D790.

Flexural tests were conducted at ambient temperatures on a computer controlled Instron UTM machine (5600 R) using $\pm 50 \mathrm{kN}$ load cell and a ramp rate of $2 \mathrm{~mm} / \mathrm{min}$ in the laboratory air atmosphere. All the tests were conducted under 3-point bend loading. The variation of specimen displacement (from the ramp position) and the load values were dynamically recorded in order to obtain the flexural stress-strain data at ambient temperature, which was used to determine the flexural strength properties.

\section{Results and discussion}

\subsection{Microstructure}

The arrangement of carbon fibres was observed using a scanning electron microscope (SEM) of $20 \mathrm{kV}$ (the composite did not respond to microscopes with voltage capacity lower than $20 \mathrm{kV}$ ). The carbon fibres were found to be continuous throughout the matrix aligned unidirectionally, with high volume fraction of fibres. The CNTs were not visible due to the lower resolution. The average diameter of the carbon fibre was $6 \mu \mathrm{m}$ (figure 2(a)). Fibres were physically distinguishable and were not found

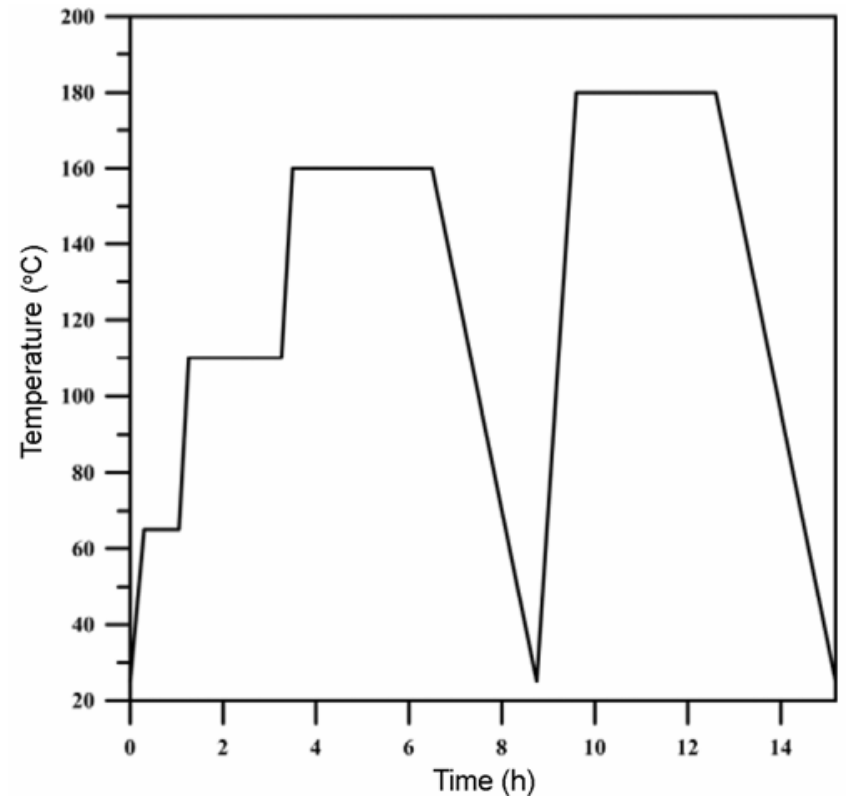

Figure 1. Heat treatment cycle for curing of composite. 

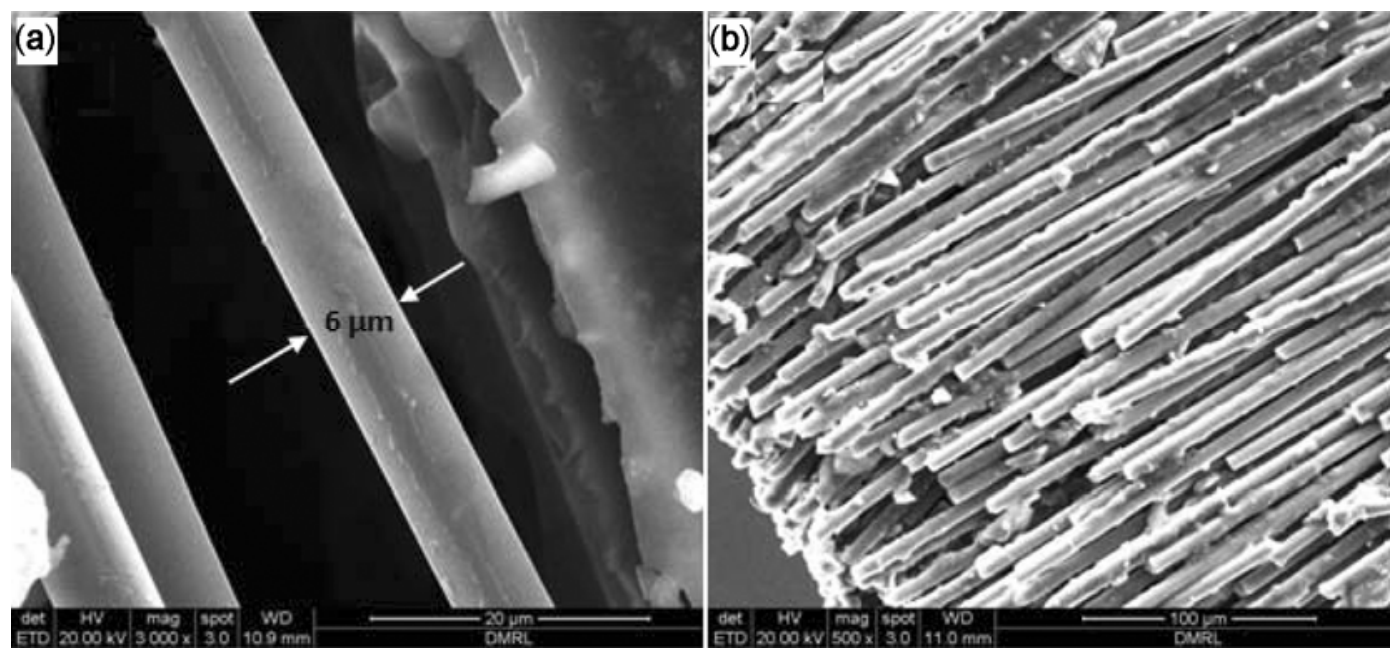

Figure 2. SEM micrographs of carbon fibres in hybrid composite: (a) single carbon fibre and (b) carbon fibre bundles.

Table 1. Physical properties of hybrid composite.

\begin{tabular}{lll}
\hline Sl. No. & \multicolumn{1}{c}{ Physical property } & Value obtained \\
\hline 1 & Density & $1.56 \mathrm{~g} / \mathrm{cc}$ \\
2 & Fibre volume fraction & $82.05 \%$ \\
3 & Young's modulus (longitudinal) & $16 \cdot 31 \mathrm{GPa}$ \\
4 & Young's modulus (transverse) & $15.9 \mathrm{GPa}$ \\
\hline
\end{tabular}

diffused into one another in spite of three heat treatment cycles. Figure 2(b) clearly shows no disturbance or breakage among fibres was observed until and up to fabrication stage.

\subsection{Physical properties}

The composite was subjected to various types of testing in order to determine the physical properties such as density, Young's modulus and fiber volume fraction at ambient temperatures of the composite. The Young's modulus was determined by the rule of mixtures in both the orientations given by:

For longitudinal orientation:

$$
E_{\mathrm{c}}=E_{\mathrm{m}} V_{\mathrm{m}}+E_{\mathrm{r}} V_{\mathrm{r}},
$$

and for transverse orientation:

$$
E_{\mathrm{c}}=E_{\mathrm{m}} E_{\mathrm{r}} /\left(E_{\mathrm{m}} V_{\mathrm{r}}+E_{\mathrm{r}} V_{\mathrm{m}}\right),
$$

where $E_{\mathrm{c}}$ is the Young's modulus of the hybrid composite, $E_{\mathrm{m}}$ is the Young's modulus of the matrix, $E_{\mathrm{r}}$ is the Young's modulus of the reinforcement, $V_{\mathrm{m}}$ is the volume fraction of the matrix and $V_{\mathrm{r}}$ is the volume fraction of the reinforcement. The results thus obtained are as follows.

From the data in table 1, it can be seen that the composite showed an isotropic behaviour because of approximately same values obtained for Young's modulus. This can be attributed to the presence of high carbon fibre volume fraction.

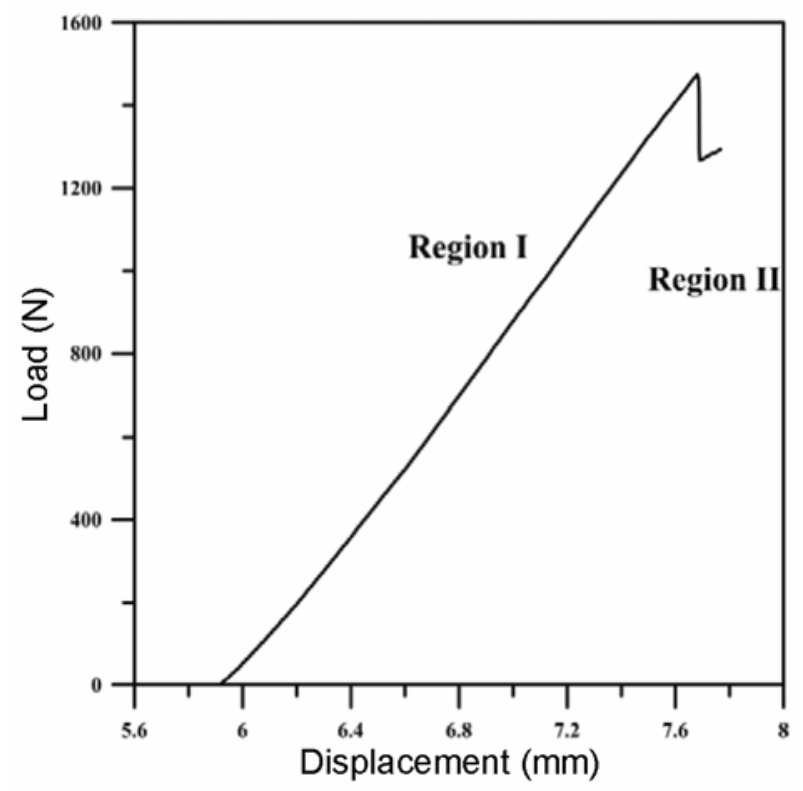

Figure 3. Load vs displacement data for flexural strength (3-point bend loading) test in longitudinal orientation.

\subsection{Flexural strength testing}

Flexural test in 3-point bend loading were conducted on specimens of width $(b)$ of $10 \mathrm{~mm}$, thickness $(d)$ of $3.4 \mathrm{~mm}$ and length $(L)$ of $75 \mathrm{~mm}$ (with an included span length equivalent to 16 times the thickness). A total of 10 specimens were tested and here only one specimen loaddisplacement data is being shown for sake of clarity in each cases, i.e. longitudinal and transverse orientations.

3.3a Longitudinal orientation: It can be clearly seen from table 2 that the material possesses excellent flexural strength in the longitudinal direction with an average value of $1084 \mathrm{MPa}$. This can be attributed to the presence 
Table 2. Dimensions of specimens used and values of flexural strength of hybrid composite in longitudinal orientation.

\begin{tabular}{lccccc}
\hline $\begin{array}{l}\text { Sl. } \\
\text { No. }\end{array}$ & $\begin{array}{c}\text { Width } \\
(\mathrm{mm})\end{array}$ & $\begin{array}{c}\text { Thickness } \\
(\mathrm{mm})\end{array}$ & $\begin{array}{c}\text { Length } \\
(\mathrm{mm})\end{array}$ & $\begin{array}{c}\text { Max. load } \\
\text { applied }(\mathrm{N})\end{array}$ & $\begin{array}{c}\text { Flexural } \\
\text { strength (MPa) }\end{array}$ \\
\hline 01 & $10 \cdot 10$ & $3 \cdot 25$ & $74 \cdot 93$ & $1474 \cdot 51$ & 1120 \\
02 & $10 \cdot 17$ & $3 \cdot 30$ & $75 \cdot 10$ & $1473 \cdot 44$ & 1078 \\
03 & $10 \cdot 13$ & $3 \cdot 27$ & $74 \cdot 86$ & $1476 \cdot 31$ & 1104 \\
04 & $9 \cdot 72$ & $3 \cdot 53$ & $75 \cdot 11$ & $1405 \cdot 99$ & 1089 \\
05 & $10 \cdot 11$ & $3 \cdot 30$ & 74.96 & $1379 \cdot 37$ & 1015 \\
06 & $9 \cdot 91$ & $3 \cdot 23$ & $75 \cdot 05$ & $1400 \cdot 41$ & 1097 \\
\hline
\end{tabular}
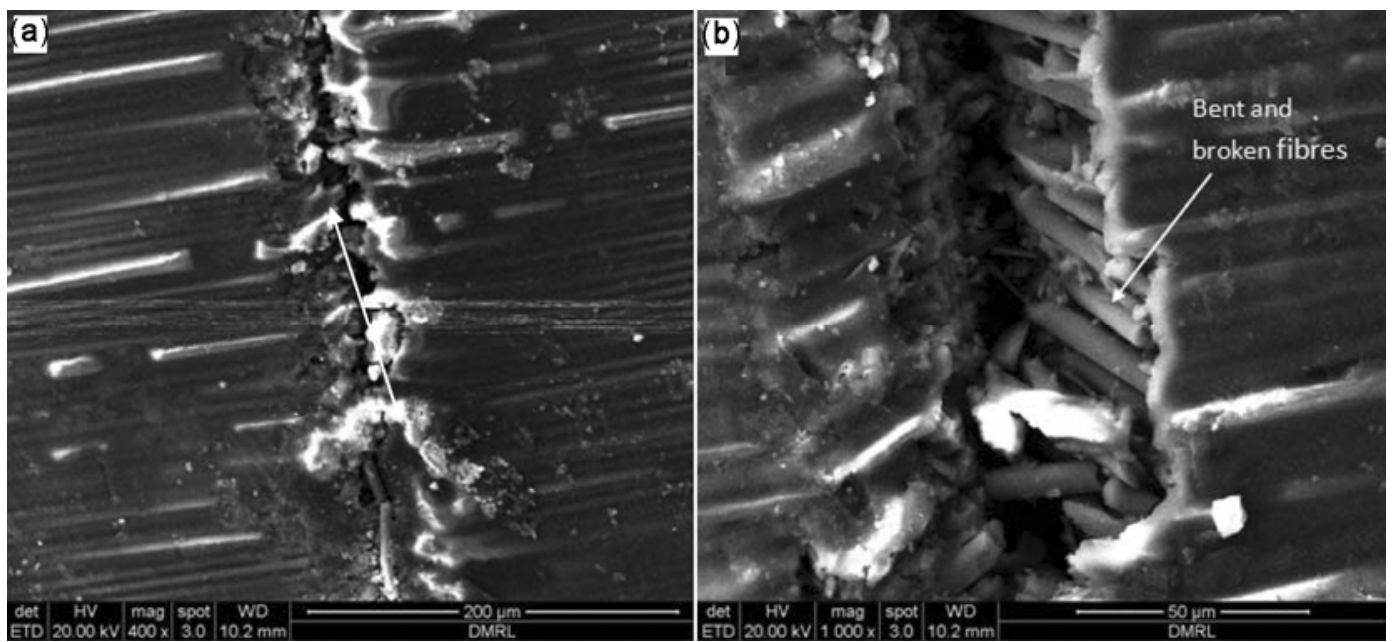

Figure 4. (a) Crack path observation after flexural testing in longitudinal orientation and (b) bending and breakage of surface fibres observed after test.

of the light weight carbon fibres and also the particulate reinforcement, the CNT. Typical load vs displacement curve (as in figure 3 ) for one of the specimens explains the exceptional behaviour of the material. The plot exhibits a gradual increase in the load along with increase in displacement up to a peak point and then shows a steep decrease with falling slope. The gradual increase in the elastic zone is due to the presence of fibres perpendicular to the direction of crack propagation and also due to the CNT, which take up the load completely (Region I). This is followed by Region II consisting of a sharp and steep fall in the stress value at approximately constant displacement. This stage is largely dominated by shear mode of failure. This is followed by a small increase in the load after this steep decrease which can be assumed as the building up of resistance by the surrounding fibers or contribution of CNTs. The mechanism of the stress distribution in the hybrid composite can be explained in the following way: firstly, a group of fibres (at the surface), experiences the maximum stress initially by taking up the load completely. This is the elastic stresses zone (Region I). On further increase in the load, the surface fibre bundle breakage starts leading to the crack initiation and instant propagation and with participation of other fibres beneath the surface. With the failure of these fibres, the other fibres start experiencing the stress and further crack propagation is carried out (marked by the rise in the plot in Region II). The data in figure 3 shows a displacement starting from $5.9 \mathrm{~mm}$ (approximately) until the $7.9 \mathrm{~mm}$ till the test is interrupted. Till $5.9 \mathrm{~mm}$, it is the cross head displacement that is progressed at zero load and thereafter the load string and the specimen start experiencing the load. Table 2 gives the overall information regarding the testing carried out in longitudinal orientation.

The crack propagation direction is across the length of the specimen as shown in figure 4(a). The microstructures obtained for the crack path of the tested specimens in this orientation clearly shows the breakage of fibres which are perpendicular to the crack propagation (see figure 4(a)). Also, these specimens exhibited the clear bending and breaking of the stressed surface fibres into them. This suggests the above explanation is justified (figure 4(b)).

3.3b Transverse orientation: Load vs displacement data was plotted for the transverse loading for one of the specimens tested. Here, it was observed that the flexural strength is significantly lesser $(3-4 \%)$ when compared to 
Table 3. Dimensions of specimens used and values of flexural strength of hybrid composite in transverse orientation.

\begin{tabular}{lccccc}
\hline S1. No & $\begin{array}{c}\text { Width } \\
(\mathrm{mm})\end{array}$ & $\begin{array}{c}\text { Thickness } \\
(\mathrm{mm})\end{array}$ & $\begin{array}{c}\text { Length } \\
(\mathrm{mm})\end{array}$ & $\begin{array}{c}\text { Max. load } \\
\text { applied (N) }\end{array}$ & $\begin{array}{c}\text { Flexural } \\
\text { strength (MPa) }\end{array}$ \\
\hline 01 & $10 \cdot 33$ & $3 \cdot 53$ & $75 \cdot 26$ & $54 \cdot 49$ & 34 \\
02 & $10 \cdot 11$ & $3 \cdot 45$ & 74.93 & $48 \cdot 20$ & 32 \\
03 & $10 \cdot 41$ & $3 \cdot 38$ & $75 \cdot 19$ & $63 \cdot 13$ & 43 \\
04 & $10 \cdot 45$ & $3 \cdot 43$ & $75 \cdot 10$ & $66 \cdot 91$ & 44 \\
\hline
\end{tabular}

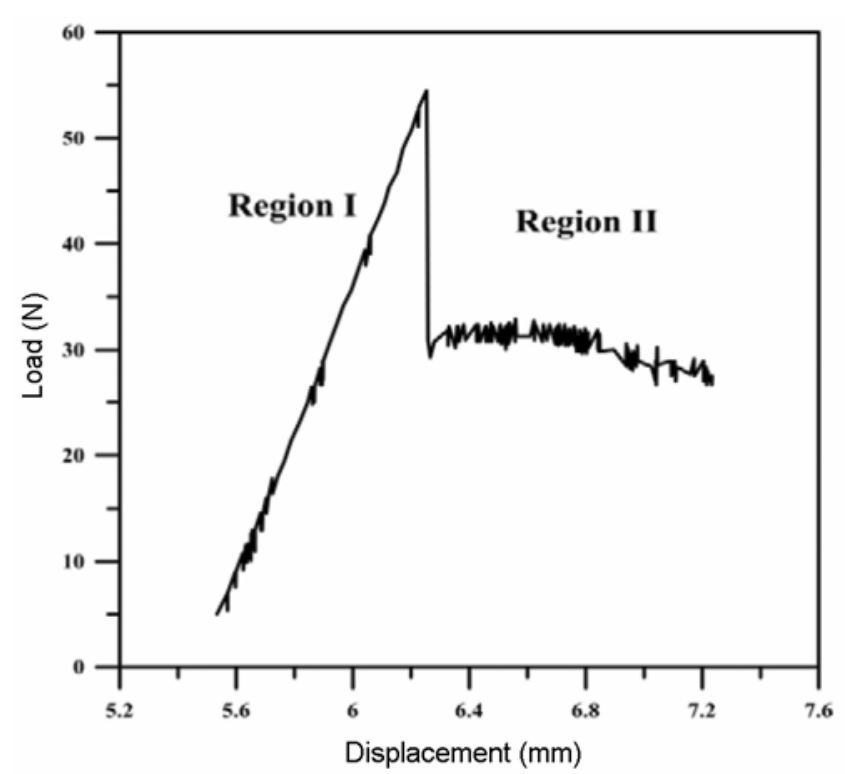

Figure 5. Load vs displacement data for flexural strength (3-point bend loading) test in transverse orientation.

the longitudinal direction. The average flexural strength obtained in this orientation is $38 \mathrm{MPa}$ approximately. This phenomenon occurs because the fibres are aligned parallel to the propagation of the crack and, thus, their participation is largely neglected. The crack path is largely straight enough to justify this statement. The matrix takes up the entire load and the maximum load value exhibited here is the load taken by the matrix (epoxy and CNTs) alone. Perhaps, the values would degrade even more in the absence of CNTs in the resin mixture, which hinders the crack propagation.

The graph plotted for the transverse alignment of fibres under 3-point bend loading exhibits a similar behaviour when compared to the longitudinal orientation except the fact that the load bearing capacity is very low here. It is interesting to note the scale of both the axes. In this plot in figure 5, 'Region I' exhibits the elastic nature of the material and the load increases with increase in displacement. Mild serrations can be observed in this region, which could have resulted due to the presence of CNTs. The poor strength properties of matrix are being compen- sated by the CNTs in the matrix mixture. 'Region II' shows a more steep and large fall in load and then attains near saturation in load, with an increase in displacement. It can be noted that there is even a more severe serrations region formed in the load displacement data after the steep load drop which can be attributed to the presence of CNTs in the matrix. This could be assumed as a resistance build with a large displacement until the total fracture of the specimen.

In this orientation, with a small increase in load/stress, there is a large increase in displacement owing to the poor strength of the matrix mixture. It is observed that the maximum average load level of this composite in transverse orientation is $58 \mathrm{~N}$ approximately which corresponds to a flexural strength of $38 \mathrm{MPa}$. Table 3 gives the overall information regarding the testing carried out in this orientation.

The microstructures observed for the crack path was observed straight to the naked eye and also the SEM analysis revealed no significant lateral damage to the carbon fibres as seen from figures 6(a) and (b).

\subsection{Directionality in strength properties}

From the above tests conducted and results obtained, it is clear that a hybrid composite such as $C_{\mathrm{f}}$ (unidirectional) and CNT reinforced epoxy matrix composite possesses significantly higher flexural strength in the longitudinal orientation, compared to the transverse orientation. It can be clearly seen in the load vs displacement curve in figure 7 plotted for both orientations.

Though a similarity can be observed in the curve behaviour, there is a huge disparity in the stress bearing capacities in both the orientations. The hybrid composite showed an isotropic behaviour from table 1 in Young's modulus, but there is a definite directionality influence on strength properties. This arises from the presence of unidirectionally wound fibres whose Young's modulus is approximately same $(17 \mathrm{GPa})$ in the longitudinal orientation and $(16 \mathrm{GPa})$ in the transverse orientation. Fibres have a dominant effect in this orientation resisting the crack propagation. The matrix fails in resisting the crack propagation when load is applied in the transverse orientation. 


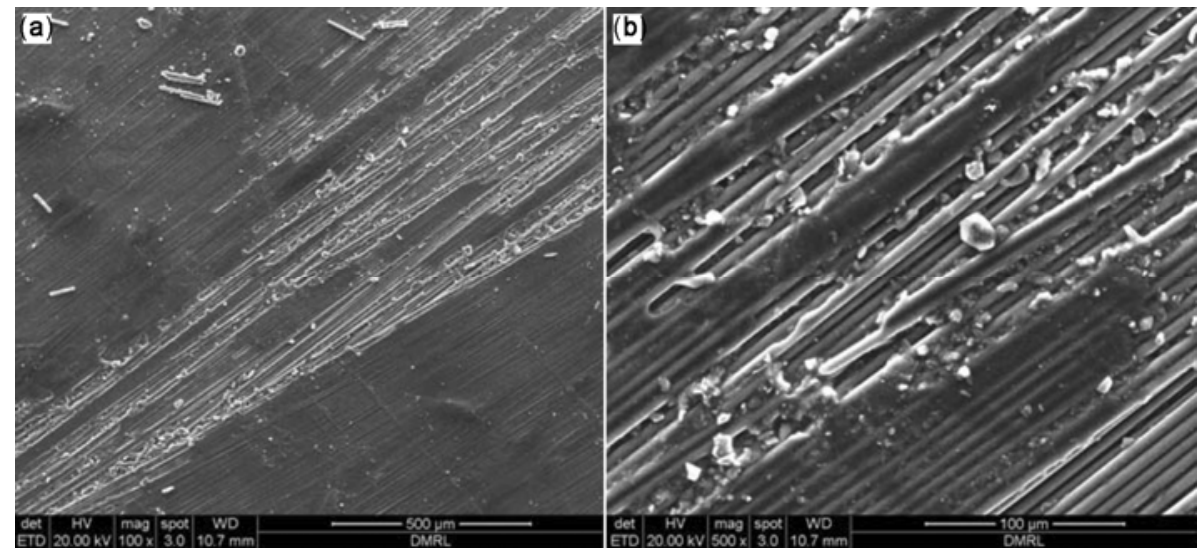

Figure 6. Crack path observation after flexural testing in transverse orientation: (a) At $100 \times$ magnification and (b) at 500× magnification.

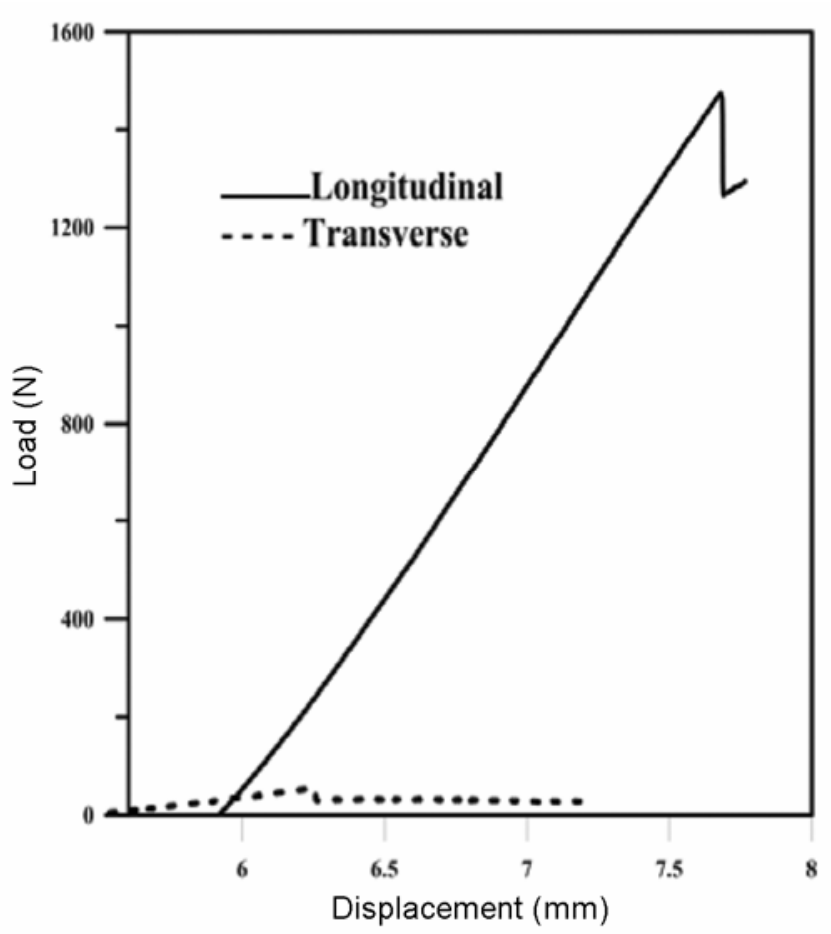

Figure 7. Plot vs displacement data for flexural strength (3-point bend loading) test for longitudinal and transverse orientations.

\section{Conclusions}

The unidirectional $C_{\mathrm{f}}-\mathrm{CNT}$ reinforced epoxy matrix hybrid composite was successfully processed by hand lay up technique. The hybrid composite was tested for its physical properties and it showed a very less density when compared to other competing PMCs used in the structural applications. The flexural strength of the hybrid composite is significantly higher in longitudinal orientation as compared to the same in transverse orientation (1084 MPa in the longitudinal orientation). Thus, the composite showed an appreciable influence of fibre ori- entation. These properties obtained from the hybrid composite show that it is clearly suitable for structural applications in the aeronautical and aerospace industry, where the exceptionally high values of longitudinal flexural strength can be exploited.

\section{Acknowledgements}

The authors would like to profoundly thank Dr V G Sekaran, Distinguished Scientist and Director, ASL, for allowing them to use the material processing facilities for the preparation and testing of the present hybrid composite. They also wish to acknowledge the active participation of M. Naveen Kumar and N. Krishna Kanth of MGIT, Hyderabad. One of the authors (NEP) is grateful to Dr K Tamilmani, Distinguished Scientist and Chief Executive (Airworthiness), CEMILAC, for his kind support.

\section{References}

ASTM Standard D 3171-11 Standard test methods for constituent content of composite materials; Annual Book of ASTM Standards (West Conshohocken, PA: American Society for Testing and Materials)

ASTM Standard D 790-10 Test Methods for Flexural Properties of Unreinforced and Reinforced Plastics and Electrical Insulating Materials Annual Book of ASTM Standards American Society for Testing and Materials, West Conshohocken, PA

Chandra Shekar K, Naveen Kumar M, Subramanian P K, Anil Kumar, Anjaneya Prasad B and Eswara Prasad N 2013 Trans. Indian Inst. Metals doi: 10.1007/s 12666-013-0312-4

Eswara Prasad N, Sweety Kumari, Kamat S V, Vijayakumar M and Malakondaiah G 2004 Eng. Fract. Mech. 712589

Herrera-Franco P J and Valadez-González A 2004 AIChE 35 339

John J Brennan and Karl Prewo 1982 J. Mater. Sci. 172371

Timothy Gutowski, David Hoult, Greg Dillon, Ein-Teck Neoh, Stuart Muter, Eric Kim and Mawuli Tse 1994 Comp. Manuf. 5231 